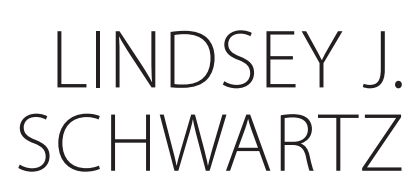

\title{
International Educational Justice: Educational Resources for Students Living Abroad
}

\begin{abstract}
As a result of globalization, the number of people living outside of their countries of origin is on the rise. Among them are children of primary and secondary school age of varying socio-economic backgrounds. This article addresses the education-related challenges that children in such circumstances face. I first identify two principles - an educational adequacy principle and a presumption of responsibility on the part of a host country for meeting children's educational needs - which are widely employed to guide national policy decisions on educational content and the distribution of educational resources. I then discuss a number of problems that students living abroad face which, I argue, policies devised on the basis of these principles either systematically overlook or, in some cases, exacerbate. Finally, I offer two alternative principles - a cosmopolitan revision of the first and a replacement for the second with a focus on collective responsibility - designed to promote education policies better suited to a globalized world which might help to alleviate the barriers to success commonly encountered by children learning abroad.
\end{abstract}

Keywords: education; educational justice; educational resources; migrant rights; transnational education.

\section{Introduction}

Globalization has rapidly and significantly changed the ways in which both individuals and national governing bodies operate with respect to each other and the world's intellectual and material resources. Notably, it has changed the number and socio-economic profiles of people living outside of their nations of origin. Concerns arising as a result of this change, specifically those regarding the resources necessary for adequate educational attainment among international students, are the subject of this article. ${ }^{1}$

An ever-increasing number of people, whether by choice, circumstance, or necessity, wind up residing beyond the borders of their national homelands, at least for a time, and included in their ranks are children of primary and secondary school age. ${ }^{2}$ Given a common national commitment among a plurality of rich and poor countries alike to provide their citizens with a robust, public primary and secondary education, how should these states handle their

1 For the purposes of this paper, the term 'international students' refers to students being educated outside of their countries of origin, students living outside of the countries in which they are educated, transnational migrants of school age, and any other student or would-be student whose (potential) educational circumstances could reasonably be classified as studying abroad.

2 According to the Migration Policy Institute (2019), '[i]nternational migration has more than tripled in size since 1960.' The UN puts the current number of international migrants at roughly 258 million, up from around 77 million in 1960, and counts 36.1 million children among the 258 million current international migrants (UN DESA, 2017; Migrant Policy Institute, 2019; Mosler Vidal and Dag Tjaden, 2018). 
would-be students living abroad? That is, to what educational resources are these children entitled? ${ }^{3}$ And who or what entity is obliged to provide them? Taking these basic questions as its starting point, the paper proceeds as follows.

The next section of the paper explicates the methodology of the paper. The paper is an instance of non-ideal theorizing. This section outlines exactly how I understand non-ideal theorizing, and, through the explanation of the paper's methodology, establishes answers to the two basic questions posed above. I argue that nations that provide and, in some cases, compel participation in public education are generally committed, to varying degrees, to providing (a) equal educational opportunities (b) for all of the children of school age for which they are responsible, and that embedded in that commitment is an implicit commitment to providing a good education, which is gauged by (3) all students having met an adequacy threshold. The section culminates in the identification of two questions specific to the circumstances of international students that are left unaddressed by these commitments.

In the following section I consider two of the more dominant principles guiding education policy today. The first guides decisions regarding educational content; the second informs decisions about which students belong to which school system and what entities are responsible for them. After motivating each, I present several cases that collectively illustrate the ways in which these principles consistently neglect and thereby fail to secure equal educational opportunities for, specifically, international students. The cases I present are largely U.S.-centric, but aside from the occasional use of U.S. legal precedent to provide contextual insight into local policies, I believe the circumstances they demonstrate easily generalize. They draw out the kinds of challenges international students in any country and from any country who find themselves in similar situations are likely to face.

The set-up constructed in the previous two sections provides the basis for the primary argument of the paper in the next. I argue that if those nations providing education as a public good are in fact committed to the goals detailed in the second section, and the cases detailed in the third show that those commitments are not, in many cases, being met, then those nations face a practical trilemma. They can: give up their commitment to the provision of equal educational opportunities for all; give an acceptable, principled explanation as to why the students who are not provided equal educational opportunities are

3 Educational resources is a catch-all term for a wide variety of components that contribute to a full education. It often includes things like one-on-one time with teachers, emotional support, etc. For the purposes of this paper, I limit the scope of the term to the kinds of resources that can be provided at the state level. This includes financial resources, educational materials, curriculum standards, and things like hiring standards and practices. It must, however, exclude the kinds of resources provided at the classroom level. 
relevantly different from those who are; or they can keep the equal opportunity commitment and grapple with a number of challenges brought out by those cases in which they are failing to meet their educational commitments to the international student for whom they might bear some responsibility.

I table the first two options in order to go into greater detail on the third. To that end, I offer two principles of action that I take to be politically feasible which might, if properly enacted, help to overcome the challenges detailed earlier, and then consider what it might look like for these to be 'properly enacted.' This involves preliminarily canvassing certain policy prescriptions that might be implemented on the basis of the principles offered. I conclude the paper with a forecast of further practical complications that may arise if the principles/ practices that I recommend were to be enacted.

I want to preface the argument by acknowledging two limitations. Space limitations restrict the level of detail I can provide on the various intricacies of the topic. The same preclude considering objections that may challenge what I put forward here. This is, however, a burgeoning topic. I expect that additional details will come to light as it grows. I also expect that one of the things this discussion will generate is a fair body of objections to what I offer. I hope that both of these outcomes materialize. My aim is not to resolve this topic, but to contribute both to its introduction and to an ongoing conversation about it.

\section{Methodology}

This paper is a case of non-ideal theorizing; it engages with circumstances in the world as they now stand, not with circumstances as they ideally ought to be. ${ }^{4}$ Given different background conditions, the particular problems I am concerned with might not have arisen, or others might have instead. I am interested in what the world is actually like, and what those of us living in it can do to overcome the challenges it presents. The goal when engaging in nonideal theorizing is to identify principles of action that apply when we do not expect to eliminate certain injustices that are embedded in the circumstances in question. Sometimes non-ideal theorizing aims to offer practical solutions, but doing that is beyond the scope of this essay: I want to raise a collection of related challenges in an area of educational justice that has not garnered a great deal of attention, and to offer principled ways to approach these challenges given the non-ideal (read: unjust) circumstances in which we currently find ourselves. Some amount of philosophical progress can be made by simply bringing new

4 For explanations of ideal versus non-ideal theory, see Rawls, 1971, 1999, and 2001. See also Freeman, 2007 : 472. The general thrust of the distinction is that whereas ideal theory examines what a world free of injustice would look like, non-ideal theorizing devises principles of action aimed at realizing the ideal to the greatest extent possible under conditions of persistent injustice. As Rawls succinctly puts it, 'we look to non-ideal theory to find the least unjust scheme' (1999: 43). 
challenges into the light and offering a way in which to engage with them. The point of this exercise is to offer a philosophical treatment of a pressing social problem that is of practical, and not just theoretical, significance. The jumping off point for any instance of non-ideal theorizing is to identify which parameters to hold fixed. These will be the non-ideal background conditions within which I am obliged to work as I attempt to put forward certain principles of action to accomplish a state of affairs that is as just as we can expect it to be, given the injustices that we expect to persist (at least for the time being). For the purposes of this paper, I accept the following non-ideal parameters - which is to say, the following unjust circumstances - as, at least for the foreseeable future, unlikely to change, and therefore as not addressed, but rather accommodated by my paper.

My discussion is limited to those countries that are committed at least politically (via their standing national education policies) to providing universal public education, whether compulsory for a time or not, to the children of school age for whom they are responsible. I take for granted that resources distributed for the purposes of public education are government resources, and that government resources are limited - more limited in certain countries than others. A governing body's carrying capacity matters morally just as much as the personal and positional interests individuals have in acquiring an education. As with any resource, if it is overextended it can be lost for good, and then no one stands to benefit from it. If ought implies can, then limitations on government resources are morally relevant. The upshot of this is that not every sovereign nation is or can be expected to be capable of providing unlimited educational resources. That fact is especially relevant when deciding from where the resources for international students ought to come.

While a majority of governments are interested to ensure that their citizens (and in many cases, the non-citizen members of their respective societies) are well-educated, they might be so for different reasons and to differing degrees. Brighouse et al. (2018: 19-29) lay out a conception of educational goods sufficiently general to capture the aims of public education across varied sociopolitical contexts, which lends itself nicely to a discussion of international educational issues. On their conception, educational goods just are the knowledge, skills, dispositions, and attitudes necessary for the development of a number of capacities ranging from economic productivity to healthy interpersonal/social skills and personal fulfillment, ultimately aimed at human flourishing. The generality of their conception of educational goods is meant to accommodate the fact that exactly what constitutes an appropriate set of skills, or what kind of knowledge a school ought to impart, ultimately depends 
on social context (Brighouse et al., 2018: 22). In liberal and social democratic regimes, governing bodies are interested both to create economic output and to produce well-informed participants in systems of self-governance. In undemocratic regimes - theocratic or authoritarian regimes, for instance - the governing bodies are at least interested in producing compliance and economic results via public education programs. Regardless of their ultimate aims or what kinds of social systems they are interested to perpetuate, they share an interest in educating as much of the population as possible via universal (often compulsory) public education systems. This commitment, I take it, is enough to establish a right to public education. While there may be plenty of other factors that underpin a right to education (autonomy interests or the ability to pursue one's own conception of the good, for instance), the fact that the government has committed itself to providing and, in many cases, compelling participation in public education is, for my purposes, sufficient to establish an entitlement. ${ }^{5}$

I further take for granted that education is, in part, a positional good, that some students will get a better education than others based on the kind and quality of education available to them where they live, and that inequalities above a basic adequacy threshold regardless of geographical location are bound to persist. This means that not every international student can be expected to benefit equally from his or her education abroad. It does not, however, preclude the possibility of mitigating the disparities between their outcomes via some form of standardization. The professed goal among the nations that make up the target group of this discussion is often the provision of equal educational opportunities for all students, but embedded in that goal is the commitment to meeting some threshold of adequate educational attainment. It would obviously be a waste of resources to provide everyone with an inadequate education, but what exactly constitutes an adequate education is often left un- or ill-defined. Still, where the adequacy threshold is set matters a great deal for students being educated outside of their countries of origin.

Finally, I take it that the often unjust factors driving current migration patterns, including return migration whether voluntary or coerced, will persist for the foreseeable future. Poverty, war, and political and gang violence will continue to drive people from their homelands, and ill-equipped immigration and refugee resettlement policies and procedures will continue to leave people precariously displaced in long-term, but still temporary living situations. Things like better economic prospects, better living conditions for people with historically

5 Contractualism may not withstand scrutiny as a comprehensive moral doctrine, but it accurately describes and effectively guides many aspects of political life, especially the relationship between the governed and those doing the governing. Part of what stabilizes any government is that the people agree to (or in some cases, perhaps reluctantly, but willingly submit to) its policies. 
oppressed sexual orientations or social identities, and better educational opportunities will also continue to motivate transnational migration. Those who choose to and those who must are going to continue seeking better lives abroad, and some of them will wind up doing so through improper channels. Immigration and deportation policies are not likely to undergo significant enough changes to cause a major shift in migration patterns. Nor is the nature of conflict likely to undergo such changes. In short, the number of school age children living outside of their countries of origin is more likely to grow or, at least, to remain at its current levels than it is to shrink over the next 20-50 years, in part as a result of numerous intractable, global injustices. ${ }^{6}$

The foregoing parameters establish that children of school age who are members of one or more of the nations in the group here delineated have a legitimate claim to educational resources provided by their governments. The very same parameters both expose and leave open two particularly vexing questions regarding international students:

Since education is a public good provided by the governments of independent nations, by what (set of) principle(s) should we determine to what nation an international student belongs, if only for the purposes of securing educational resources?

Given the impermanence or instability of many of these students' living situations, what principle(s) should guide those who are responsible for their education to ensure that they are well-equipped to thrive wherever it is they ultimately wind up living?

It is to these two questions that the principles I criticize in the next section and those I subsequently offer correspond.

\section{Educational Adequacy and Host Country Responsibility}

The educational commitments I ascribe to the argument's target group of nations are few, but broad. I have so far stipulated that the nations in question are those that are committed (at a minimum by standing public policies) to the universal provision of public education, and have noted that the oft-professed goal of these nations is to provide equal educational opportunities for all those children of school age for which they are responsible. I have explained why I take these commitments to be sufficient for a de facto right to public education, and why they very probably entail commitment to a certain threshold of educational attainment. I have not addressed any specifics as to curriculum content, what constitutes adequate educational attainment, or how educational system

6 For both quantitative and qualitative analyses of global migration projections, see OECD, 2009; Sander et al., 2013; and UN DESA, 2019: 32-35. 
membership and governmental responsibility for students are determined. The goal of this section is to examine the principles that are typically applied to fill in these specifics today.

Recall Brighouse et al.'s conception of educational goods as knowledge, skills, dispositions and the like, the acquisition of which are ultimately aimed at a flourishing life. This, in part, provides the substance of (at least one iteration of) what is known as the adequacy model of educational justice. ${ }^{7}$ The adequacy model, broadly speaking, seeks to ensure that students who complete their educational programs are thereby equipped to "participate fully in the society in which they reside and to live with dignity there' (Stojanov, 2018: 37). In other words, an education is adequate insofar as it bestows upon its recipients educational goods sufficient to ensure that a flourishing adulthood is not just possible in their society, but probable. Notice where the threshold is set on this view: an adequate education is defined by acquiring educational goods sufficient to ensure full, dignified membership in the society in which the student resides.

The adequacy model is attractive in part because of its adaptability. It takes into account social and cultural differences between both countries on the whole and the various communities that may exist within them. Whether a person lives in a diverse culture, a homogeneous culture, a closed culture, an honor culture, an orthodox religious culture, etc., an adequate education on this model is one that will prepare her with the kinds of knowledge, skills, and dispositions she needs to do well as a part of it. It is also aspirational. It aims for something a little higher than the bare minimum needed to get by. The goal is to ensure a dignified and connected existence in one's community, which a mere elementary level education cannot guarantee. In this way it fosters a kind of social prosperity: as more and more members of a society do well, that society as a whole benefits. This may not be how every nation that offers or compels public education in fact measures the adequacy of the education they provide, but it does represent something of a gold standard when it comes to educational justice, and it does appear to guide the educational goals of pretty much every developed nation.

The second principle that I take to be more or less standardly followed among the nations in question is what I'll call the presumption of host country responsibility. This principle says that the host country - that is, the country

7 A number of versions of the adequacy model exist which differ regarding what an 'adequate education' ought to be adequate for. Debra Satz (2007) and Elizabeth Anderson (2007) conceive of educational adequacy as adequacy for democratic citizenship. Brighouse et al. (2018) advance their conception as adequacy for a flourishing life. I take the latter to be more adaptable to a variety of different socio-political structures than the former, and thus take it to be a more fitting jumping off point for an argument that is meant to appeal as widely as possible, including to nondemocratic regimes that provide or compel public education. 
doing the receiving of migrant children of school age - ought to be held responsible or take responsibility for providing them with educational resources and opportunities. The basic thought underlying this principle is that a country bears responsibility for educating those who reside within its borders. Good reasons abound for fairly uncritical acceptance of this principle. Historically speaking, the countries receiving migrant children have, in general, been wealthier than the countries from which they departed (UN DESA, 2017: 9-14). The educational systems in migrants' host countries have usually been more comprehensive and better funded than those in the countries from which they came, and those systems have generally been quite capable of absorbing a sizable influx of new students from time to time. Recall that resource abundance is a morally relevant factor when it comes to deciding who ought to be responsible for the education of migrant students. If it has standardly been true that migrant students are leaving places with far fewer resources to contribute to educational goals and arriving in places with much greater resources already annexed to the educational systems there, it makes sense for the host country to assume responsibility for providing the educational resources they require.

In practice, a lot of educational policies cohere with these two principles. Education funds are collected from local, state, or federal taxes, and the money is then allocated to schools that fall into the corresponding jurisdiction. Curriculum is determined by the country, state, municipality, school district, etc. in which the student is to be educated. How and what a student learns varies depending on where she finds herself in the world. But the situations in which international students find themselves today, and the problems they encounter because of those circumstances, provide good reasons to question the conventional wisdom embodied in these two principles. Consider the following cases.

\section{Case (i) - U.S. Citizens living in Mexico, attending school in the U.S.}

Nearly 800 students cross the border each day from Palomas, Mexico and are bussed five miles to the town of Columbus, New Mexico to attend a U.S. school (Andavolu, 2018). These students are U.S. citizens with at least one non-citizen parent, who live in Mexico as a result of immigration policies. Their education, per the law in New Mexico, is tuition-free; the entire cost is covered by tax dollars.

A similar number of students with similar familial circumstances who cross the border every day into El Paso, Texas must, per the law, attend private schools for which their families are required to pay full tuition (Santiago, 2017). The cost of a private school education (the national average for which is $\$ 7,770$ 
USD for elementary school students and \$13,030 USD for secondary school students, per student, per school year, although some less costly options are available in El Paso [U.S. Department of Education, 2013]) can be prohibitive for parents living and working in border towns in Mexico, which might offer fewer lucrative employment opportunities than those available in Texas (or elsewhere in the U.S.).

According to the adequacy model, these students should be taught facts, skills, and dispositions that will enable them to live dignified, connected lives in the United States even though they and their immediate family members live in Mexico. Julian Culp and Danielle Zwarthoed (2018: 6) identify this same element of educational adequacy as a sort of implicit bias (they call it the 'sedentary bias'). They describe it as a tendency 'to assume that those who are educated will stay in their country of education' which overlooks the fact that 'preparing a person to be a citizen in one country does not require the same educational policies as those required to prepare this person to be either a citizen or a non-citizen immigrant in other countries.' The same bias is present in the presumption of host country responsibility, which is not even equally unhelpful in its prescriptions in these circumstances. It has no way of answering which of the two nations involved bears responsibility for these students' educational goods and resources since it is unclear which of them actually is the 'host country.' Mexico is the current home of these families of mixed citizenship, some members of which are Mexican citizens and others U.S. citizens. Thus, it is the home country for some members of the family and the host country for others. What makes the situation even more complicated is the fact that these students do not attend school in their host country. They attend school in their home country/country of citizenship. Which government, both of which profess a commitment to providing equal educational opportunities for their children of school age, should take responsibility for providing the educational resources these students both have a right to and require? The presumption of host country responsibility is silent on this question. ${ }^{8}$

Because we have no standard decision-making principle that accounts for students in such circumstances, U.S. citizens who live in Mexico, who would otherwise be guaranteed the same basic public education as any other U.S. citizen, might find themselves shut out of the system entirely unless they agree to buy at no small expense what others are offered at little to no out of pocket cost, and this in virtue of nothing more than their transnational migrant status and physical geographic location.

8 One might point to other factors (e.g., citizenship or residency) to decide which should be considered the host country for the purposes of assigning responsibility in cases like these, but appealing to the presumption itself does nothing to clear up the confusion. 


\section{Case (ii) - U.S. Citizens living overseas, attending local or U.S.-style schools.}

For students living farther away who do not have access to schools in the continental U.S., the situation is only marginally dissimilar from the previous case. Primary and secondary level students living abroad can attend U.S. style schools, most of which charge tuition and fees, with some charging fees for room and board, or they can enroll in a local, non-U.S. style school (U.S. Department of Education, 2018a). Depending on where one lives, tuition rates alone can range between $\$ 18,000$ and $\$ 50,000$ USD per student, per school year for a U.S. style school (U.S. Department of State, 2018a). Some of the U.S. style schools listed by the State Department are modestly subsidized by the host country's government - which might be a nod to the presumption of host country responsibility on the part of a nation that does not have the capacity to fully support migrant students; others rely entirely on tuition and other fees, paid in full by students' families. ${ }^{9}$ These, like the private schools Mexican residents attend in Texas, can be prohibitively costly. Should such schools be out of reach for a family living abroad, school-age children must either be home schooled or attend local schools instead.

For students in circumstances like these whose families are unable to afford to send them to schools that resemble the ones they would attend in their home countries (for instance, students from the U.S. whose families are unable to afford tuition and other fees at a U.S. style school), the current gold standard articulation of what constitutes an adequate education is of little help. Some students who find themselves in circumstances like these might live abroad for only a few years. The education they receive for those few years may put them either ahead of or behind the peers they will rejoin on their return home. Others may wind up attending local schools for the majority of their educational careers only to return to their countries of origin at or near the completion of their educational programs. They may have spent nearly their entire educational careers being prepared to lead dignified and connected adult lives in a place they will ultimately leave. In some cases, the education they receive may make it very difficult to flourish when they return to their countries of origin.

Students in these circumstances are not necessarily well-served by the presumption of host country responsibility either. The countries hosting these students may not have the capacity to provide the resources migrant students require. Often, migrant students require extra resources for things like learning the local language and learning about and adjusting to a culture with which

9 See, for instance, U.S. Department of State, 2018bcde: India, Mumbai: American School of Bombay; Bangladesh, Dhaka: American School of Dhaka; Denmark, Copenhagen: Copenhagen International School; and France, Paris: American School of France. 
they may not be familiar. Much like the students in the previous case, financial constraints may shut them out of the system that would benefit them the most for the duration of their time abroad, and thereby effectively deny them the same basic education their peers receive at little or no cost at home. The presumption of host country responsibility excuses their home governments from the responsibility to ensure that they have the same opportunities for educational success as their peers at home on the basis of nothing more than their status as international students and their physical geographic locations.

I will note here that in the U.S., the vast majority of education policies, including educational resource distribution schemes, are not enacted by a central governing body, but are left up to the discretion of the governing bodies of each state (hence the difference in resources provided to the borderstraddling students in New Mexico and Texas). As a result, it is equally true that students of the same grade level and with the same citizenship who in fact reside within the borders of the continental U.S. are not guaranteed equal educational opportunities. ${ }^{10}$ This, too, is a failure of the system (perhaps arguably, but certainly by its own purported lights), but assuming it could be remedied, the circumstances of students living abroad may still pose a unique challenge. This is largely due to the problem, exacerbated by the presumption of host country responsibility, of deciding on what body responsibility for these students should fall.

\section{Case (iii) - Undocumented and immigrant students in the U.S.}

In 1982, the U.S. Supreme Court ruled in Plyler $v$ Doe that the Equal Protection Clause of the Fourteenth Amendment guarantees a student's right to a public education in accordance with State law, regardless of his or her, or his or her parents' or guardian's, undocumented status; the clause guarantees all persons within the state's jurisdiction equal protection under the law. ${ }^{11}$ Hence, undocumented students living in the U.S. are entitled to a public education, and are required to attend public schools in accordance with local laws and statutes. As things stand, roughly 65,00o undocumented immigrants graduate from high school in the U.S. each year (UCLA Center for Labor Research and Education, 2007), many or most of whom benefit from a publicly funded education.

Contrary to a common, but mistaken, assumption, the reality of migration patterns is that many people do not remain in the countries in which they are educated for the rest of their lives. In many cases, they do not remain in-country for even the duration of their primary and secondary education. Reasons for

10 For historical and legal context regarding this issue, see San Antonio Independent School District v Rodriguez (1973). 11 While the Court acknowledged its prior finding that there is no Constitutional guarantee to a public education per se (see San Antonio Independent School District $v$ Rodriguez, 1973), it maintained that states with compulsory education laws were required by the Equal Protection clause to include undocumented students under those laws. 
what is called return migration - a return to one's country of origin after a significant time abroad - vary, but they include both voluntary reasons, like seasonal or occupational migration, and involuntary reasons, like threats to a person's physical safety or deportation in accordance with local immigration laws (Espindola and Jacobo-Suárez, 2018: 54-55). For undocumented students in the United States, the possibility of experiencing a forced return looms large. In fact, many such students may cyclically emigrate and return several times over the course of their lives (ibid.). Students who are deported to countries in which they have never lived - children of deported immigrants, for instance - often face discrimination in their new schools for things like a lack of cultural knowledge, failure to assimilate, poor command of the local language, and other shortcomings related to what and how they were taught in their previous host countries (Espindola and Jacobo-Suárez, 2018: 60-61). This is partially the result of the application of the current standard articulation of the adequacy model of educational justice. Students in the U.S. are prepared to live dignified, participatory lives in the United States. They are not required to acquire proficiency in a second language, nor are they especially well-educated about other cultures. Given the long history of people migrating both cyclically and permanently between North and Central (even South) America, the lack of cultural education about Latin American countries in U.S. schools seems like an obvious oversight. Once the adequacy standard is clearly articulated, though, that such an oversight persists makes more sense.

The U.S. is the host country for hundreds of thousands of migrant students, and its Constitution guarantees a basic public education in accordance with state laws to all school age students, regardless of national origin or country of citizenship, but the U.S. is not necessarily representative of host countries in general. The presumption of host country responsibility leaves at least two important problems unsolved. First, not all host countries are as wealthy or as developed as the U.S. and may not be as well-equipped or willing to accommodate immigrant student populations, small or large. In many cases, the host country may not have the resources necessary (i.e., the capacity) to take on the responsibility of educating migrant students. What is more, the host country may not accept any legal or moral responsibility to provide educational programming for migrant students in the first place. ${ }^{12}$ Texas certainly argued against taking any such responsibility, and the decision against its refusal to admit undocumented students to public schools in Plyler (1982) relied in large

12 I use migrant students to delineate a particular subset of international students: those whose residence status is more tenuous than the average international student or whose stay will be (for whatever reason) especially short-lived. Migrant student might refer to an undocumented student, a temporarily displaced child of school age, or a school-age child who will be in-country for a determinate, but limited time, for example. 
part on close analysis of the Fourteenth Amendment's text. Had it said any citizen rather than any person within the state's jurisdiction, things likely would have turned out very differently. The fact is that even countries like the U.S. that have the resources necessary to provide each of their school age citizens an adequate education, whether in-country or abroad, may lack the bureaucratic infrastructure for funding educational programs overseas, the political will to provide adequate resources for all, or both.

One further concern on the part of the governing bodies responsible for the provision of educational resources to international students arises as a result of the presumption of host country responsibility. This one has to do with a state's return on its investment. It stems from the so-called brain drain phenomenon. Democratic states have an interest in educating the public to maintain an informed electorate, yes, but democratic and non-democratic states alike have an interest in public education because it adds to their economic productivity. States often worry that those in whom they have invested will not stick around to become the economic contributors they would like them to be, or in more specific cases, to fill much needed, but unoccupied social positions for which they have become qualified at the state's expense. This is often construed as a problem unique to higher education, but a K-12 (or equivalent) education is sufficient preparation for plenty of economically beneficial careers. Consider: where the cost of tuition, fees, and other educational resources for international students is covered, can the funding body reasonably expect to reap any benefit from its expenditures? Should a majority of the border-straddling students in Columbus, New Mexico choose to live and work in Palomas after graduation, is there legitimate cause for objection on the part of the taxpayers of New Mexico? If the U.S. government chose to subsidize tuition for U.S. style schools abroad, could it reasonably require students it has subsidized to put their acquired talents to work to the benefit of the U.S. economy after the fact? Reasonable people disagree on these matters. ${ }^{13}$

\section{Case (iv) - Rohingya refugees in temporary housing in Bangladesh.}

According to the UNHCR (2019), there are over 900,00o Rohingya refugees from Myanmar residing in camps in Bangladesh, and roughly $37 \%$ of them (over 330,00o) are children of school age. Another $18 \%$ are young children (ages 0-4) who are likely to come of school age during their time in their host country (ibid.). Although both Myanmar and Bangladesh provide and compel public education, these children's access to educational goods and resources is uncertain. Myanmar has little or no interest in educating them (they have, after

13 For a prime example, see Brock and Blake, 2015. This is a problem to which I return in the next section of the paper since brain drain worries might equally, or even more forcefully, apply under the cosmopolitan principle of adequacy that I propose. 
all, arrived where they are due to an ethnic cleansing crisis in their homeland), and Bangladesh simply cannot afford to support an additional 330,000 students with its education spending already spread thin. ${ }^{14}$

While there are many school-age children in circumstances like those in cases (i)-(iii), there are many thousands more in circumstances like those in case (iv) around the world. For these children, neither the adequacy model nor the presumption of host country responsibility are of much assistance. If ought implies can, there is no one who ought to provide them with an education in accordance with the principles at the center of this inquiry. The task of the next section is to propose a modernized version of the adequacy model of educational justice and a replacement for the presumption of host country responsibility that might better serve children in all four kinds of circumstances, no matter how non-ideal they are.

To summarize before moving forward, the challenges that arise for international students as a result of reliance on the dominant principles guiding current educational policies include (but are not necessarily limited to): failure on the state's behalf to uphold a commitment to a robust public education for all of the children of school age for which it is (or might be) responsible, seriously disparate educational opportunities for similarly situated students, the unequal capacity of different countries to accommodate international students, logistical challenges for educational resource distribution, structural and curricular challenges posed by cyclical migration patterns, and states' concerns respecting reasonable returns on their investments.

\section{A Cooperative Approach - Taking Joint Responsibility}

The foregoing cases show that the principles that standardly guide education policy in nations committed to the provision of equal educational opportunities for all systematically fail to deliver on the promise of that commitment when it comes to international students. The group of nations in question might respond to that failure in any of several ways. First, they might decide that they are not in fact committed to providing equal educational opportunities for all. Doing so would present its own set of problems. Second, they might retain the equal opportunity commitment, but deny that they bear any responsibility for children in the kinds of circumstances detailed above. This approach represents much of the status quo, but concepts like citizenship and community membership make it difficult to realistically eschew any responsibility for these children. ${ }^{15}$

14 According to the most recent data available (UNESCO Institute for Statistics, 2019), education expenditures account for $1.54 \%$ of the country's GDP (638 billion PPP\$) - roughly 267 PPP \$ per pupil per year if divided evenly among only primary and secondary level students, or 162 PPP \$ per pupil per year divided evenly among all students of school age (including pre-primary and tertiary).

15 I table discussion of justification of this claim for reasons of space. 
Moreover, the challenges they face are serious and merely washing one's hands of responsibility for them seems unnecessarily cruel. The third option is to keep the equal opportunity commitment, and do the work necessary to devise a way to meet the challenges these children face. The aim of the present section of the paper is to offer two principles that might help with that work.

One feature common to all of the challenges raised in the last section is that each is shared by at least two nations. Parties to these problems include both the host country and the country of origin. ${ }^{16}$ Consider this shared problems feature as it pertains to the suggestion made by Juan Espindola and Mónica Jacobo-Suárez (2018) in response to a number of the problems faced by migrant students upon returning to their countries of origin. Returning students often face cultural barriers to assimilation, as well as language barriers and a number of other obstacles. Espindola and Jacobo-Suárez (2018: 64-66) suggest that, in anticipation of these problems, immigrant students should be provided with curricula that would enable them to easily assimilate in the event of a return to their countries of origin. But which country should bear the cost of the extra educational programming? As things stand, the host country has no reason to encourage or make it easier for students it has spent the time and money educating to return to their countries of origin, and their countries of origin have little reason to provide such programming, given that a return is not exactly guaranteed. But a more cosmopolitan outlook on the aims of education might give both countries a shared reason to provide the kinds of curricula Espindola and Jacobo-Suárez have in mind. To that end, I propose the following principles. ${ }^{17}$

The cosmopolitan adequacy model of educational justice: an adequate education should prepare students to participate fully in any society in which they choose to live and to lead dignified lives there. $^{18}$

The collective responsibility principle: educating migrant children is the collective responsibility of nations committed to providing equal

16 In cases of dual or multiple citizenship, the relevant parties may include multiple countries of origin.

17 Culp (2019: 54-86) advances principles very similar to these in defense of a global democratic conception of educational justice. He argues for a cosmopolitan principle of adequacy embedded in an international educational system, but our projects differ in two major respects. The first difference is at the levels of specificity. Culp's aim is to articulate an expressly democratic conception of global educational justice whereas my targets include both democratic and a variety of undemocratic political regimes. The second difference is at the level of theorizing. I take Culp's argument to be a case of ideal theory - he is out to describe what justice demands in a global educational system. My focus is on both democratic and undemocratic frameworks alike as a result of the non-ideal nature of the project. Since the persistence of non-democratic regimes is one of the parameters that I hold fixed, the principles I articulate are formulated to accommodate their particular educational aims and social norms as well. One way to view the interrelatedness of these two projects is to see Culp's as articulating the state of affairs at which our policies should ultimately aim, and mine as articulating principles designed to work incrementally toward that ideal.

18 Though inspired by Espindola and Jacobo-Suárez, this version of the principle differs from theirs insofar as it does not necessarily require differential educational programming depending on one's migratory status. 
educational opportunities for all children of school age.

The first is an update to the traditional adequacy model of educational justice. Adopting the cosmopolitan adequacy model would mean changing educational curriculum in general in order to prepare students to participate fully and live with dignity - even flourish - in any number of cultures or societies as a matter of general human capital development. It would mean cultivating adaptability as a basic life skill, and incorporating broader cultural education into existing social studies and language learning classes. It is a minor shift, but if cosmopolitanism was seen as a standard aim of an adequate education, schools might take better advantage of the cultural centers that already exist in their areas, or, where they do not already, require proficiency in a second language as part of a regular K-12 (or equivalent) education. Bringing the traditional adequacy model into the 21st century would significantly benefit students in all of the above circumstances, along with students the world over in general.

The second principle replaces the presumption of host country responsibility with a notion of responsibility better suited to a technologically advanced era, wherein physical geographic location need not limit people's options the way it once did. It also brings with it the implied wisdom that collective challenges are best met with collective action. From the shared responsibility perspective, as it pertains to the example above, it is in the interest of both the host country and the country of origin to provide curriculum that might make assimilating, at least, easier on students facing the possibility of a forced return to a country about which they may know very little. A shared goal like this one, adopted in response to a shared complication presented by the educational circumstances of a certain class of students in a globalized world, should be met with a cooperative approach. What that cooperative approach might look like is an open question.

In her work on various issues of global justice, Gillian Brock (2015, 2011, 2008) has grappled with similar resourcing obstacles, and in response to these, champions a system of targeted global taxation to fund programs that might improve things like access to clean water and healthcare, or otherwise help to alleviate extreme poverty worldwide. A targeted global taxation scheme singles out a particular kind of transaction for taxation, and reroutes the revenue the tax raises to a fund that supports a dedicated cause. For instance, the air-ticket tax is a tax on the purchase of airplane tickets that finances global health programs (Brock, 2011: 7-8). A scheme like this might be just as well-suited to meet the challenges posed in the previous section for international students.

Most (if not all) of the issues raised in this article are joint problems arising from sourcing and distribution disputes with respect to educational resources. 
A targeted global taxation scheme could go a long way toward resolving them. Enforcement might require an office situated within a global governing body, but existing offices in an international body like the UN (UNESCO, for instance) could take on collection, oversight, and allocation responsibilities for these funds without suffering a great deal of upheaval. Similar taxation schemes have been proposed in the past, including 'carbon taxes, currency transaction taxes, air-ticket taxes, taxes on arms trading,' and taxes on sales of luxury goods, and some of these have been put into effect (Brock, 2011: 7). A sufficiently welltargeted global tax on certain transactions raising money to provide resources for students living or studying outside of their countries of origin would, in itself, alleviate concerns about the capacities of individual governments to accommodate migrant students, along with those about certain risks of so-called brain drain. If neither the host country nor the country of origin is shouldering all of the risk - that is, if the financial burden is shared cooperatively among those countries that wish to provide an adequate education for all of their citizens of school age while minimizing the associated costs - these concerns drop away. ${ }^{19}$ It would further create a centralized source of funding for those international students who need it, breaking down barriers families face to securing educational funds and alleviating the logistical challenges individual funding bodies face with respect to resource distribution.

A different mechanism is international treaties. Each nation that wishes to retain its commitment to providing universal, equal educational opportunities for its children could sign on to an agreement pledging some reasonable percentage of its GDP toward educational resources for students who live abroad. No matter how such a program gets funded, having a single body handling requests for, and the allocation of resources for international students would go a long way toward securing adequate educational opportunities for students in extraordinary educational situations worldwide.

One objection to my proposal is that this kind of system might wind up primarily benefiting already well-off children whose families could easily afford to provide them with the educational resources they need without assistance. Families like this would, for instance, be better equipped to successfully negotiate whatever bureaucratic red tape comes along with the creation of this kind of office. It is a legitimate concern, but, I think, a matter of policy implementation rather than of principle. The point is, the principles on offer here can be employed to guide education policy in a way that directly confronts the challenges faced by a large contingent of school-age children around the world, while the principles

19 Though the financial costs could be mitigated with a solution like this, there remain certain - perhaps more pressing - brain drain-related challenges against which poor countries are likely to continue to struggle. I return to these briefly below. 
that currently occupy that role result in policies that systematically neglect their educational needs. Still, adopting these principles would be a mere first step toward alleviating the challenges their circumstances pose.

Once those countries that have redoubled their commitments and acknowledged the need for a cooperative solution have been counted, there will be new challenges to face at the level of international cooperation. Challenges will arise regarding exactly how a cooperative solution ought to be funded, but there will be others as well. Aside from the interest they have in providing their citizens with an adequate general education, these countries also have interests pertaining to patriotism and international economic competition that run counter to full-fledged cosmopolitanism. For instance, why should a country in the global south that is struggling with a dearth of, say, education professionals be moved to participate in a system that enables, perhaps even encourages, international mobility, especially if that mobility could exacerbate the problem ${ }^{20}$ Disputes are therefore bound to arise over the appropriate scope and content of a more cosmopolitan curriculum. Valued cultural norms, too, may be put at risk in a globalized educational environment. And a cooperative solution - a genuinely global scheme of responsibility for educating international students - might complicate concepts as fundamental as that of citizenship itself. These are all complications worth exploring in depth, but we also should not wait until their depths have been fully plumbed to start working on executable solutions. Students and nations worldwide face these challenges now, and they are likely to become more complicated as time goes on.

\section{Conclusion}

In the course of this paper, I have argued that two of the dominant principles currently guiding education policy in countries committed to providing universal primary and secondary education systematically neglect a large contingent of children of school age: international students which, broadly construed, includes any child of school age that is being educated outside of his or her country of origin or country of residence, or who has no viable option other than to be educated outside of his or her country of origin or residence, at least for a time. Based on a number of challenges students who fall under this classification face, I have proposed an amendment to one of the principles in question and a replacement for the other that I believe would, if properly implemented, directly address these students' educational needs while at the same time improving the general quality of education provided by the countries

20 One might reply that a global increase in mobility would better equip, maybe even encourage, such professionals from richer countries to fill the gaps in places like these, especially if competition for those positions is steeper in their home countries. 
in question. Though many challenges in the area remain, I take the proposal articulated herein to be an important step on a path toward a more just global educational environment. Justice cannot be secured without addressing the educational needs and circumstances of international students, along with the legitimate claims that stem from them. ${ }^{21}$

Lindsey J. Schwartz

Graduate student

University of Wisconsin-Madison

email:Ischwartz4@wisc.edu

\section{the global justicenetuork}

21 Thanks to Kathryn Joyce, Nicolas Tanchuk, Kirsten Welch, and Susanna Loeb for helpful comments on an early draft of the paper. I would also like to thank The Center for Ethics and Education for supporting the research that led to its development, and Harry Brighouse in particular for extensive comments and helpful conversations along the way. 


\section{Bibliography}

Anderson E (2007) Fair Opportunity in Education: A Democratic Equality Perspective. Ethics 117/4: 595-622.

Brighouse H et al. (2018) Educational Goods. Chicago: The University of Chicago Press.

Brock G (2015) What Does Global Justice Require? In Brock G and Blake M Debating Brain Drain: May Governments Restrict Emigration? New York: Oxford University Press: 24-35.

Brock G (2011) Reforms to global taxation and accounting arrangements as a means of pursuing global justice. Global Social Policy 11/1: 6-9.

Brock G (2008) Taxation and Global Justice: Closing the Gap between Theory and Practice. Journal of Social Philosophy 39/2: 161-184.

Brock G and Blake M (2015) Debating Brain Drain: May Governments Restrict Emigration? New York: Oxford University Press.

Culp J (2019) Democratic Education in a Globalized World: A Normative Theory. New York: Routledge.

Culp J and Zwarthoed D (2018) Introduction: Education and Migration. Journal of Global Ethics 14/1: 5-10.

Espindola J and Jacobo-Suárez M (2018) The Ethics of Return Migration and Education: Transnational Duties in Migratory Processes. Journal of Global Ethics 14/1: 54-70.

Freeman S (2007) Rawls. New York: Routledge.

Migrant Policy Institute (2019) International Migrants by Country of Destination, 1960-2017. Available at: https://www.migrationpolicy.org/programs/data-hub/charts/internationalmigrants-country-destination-1960-2017? width $=1000 \&$ height $=850 \&$ iframe $=$ true (accessed: 30 September 2019).

Mosler Vidal E and Dag Tjaden J, under the supervision of Laczko F (2018) Global Migration Indicators 2018. Berlin: International Organization for Migration Global Migration Data Analysis Centre. Available at: https://publications.iom.int/system/files/pdf/global migration indicators 2018.pdf (accessed 23 February 2020).

Organisation for Economic Cooperation and Development (OECD) (2009) The Future of International Migration to OECD Countries. OECD Publishing. Available at: https://www.oecd. org/publications/the-future-of-international-migration-to-oecd-countries-9789264064126-en. htm (accessed 23 February 2020).

Plyler v. Doe (1982) 457 U.S. 202. Available at: https://supreme.justia.com/cases/federal/ us/457/202/ (accessed 23 February 2020).

Rawls J (1971) A Theory of Justice. Cambridge, MA: Harvard University Press.

Rawls J (1999) A Theory of Justice (Revised Edition). Cambridge, MA: Harvard University Press.

Rawls J (2001) Justice as Fairness: A Restatement. Cambridge, MA: Harvard University Press. 


\section{INTERNATIONAL EDUCATIONAL JUSTICE: EDUCATIONAL RESOURCES FOR STUDENTS LIVING ABROAD}

San Antonio Independent School District v Rodriguez (1973) 411 U.S. 1. Available at: https:// www.loc.gov/item/usrep411001/ (accessed 23 February 2020).

Sander N, Abel GJ and Riosmena F (2013) The Future of International Migration: Developing Expert-Based Assumptions for Global Population Projections. Austrian Academy of Sciences. Vienna Institute of Demography Working Papers 7/2013. Available at: https://www.econstor. eu/handle/10419/97013 (accessed 23 February 2020).

Santiago L (2017) They live in Mexico and go to school in the US. CNN. Available at: https:// www.cnn.com/2017/o6/o4/americas/school-us-mexico-border-columbus-palomas/index.html (accessed: 21 July 2018).

Satz D (2007) Equality, Adequacy, and Education for Citizenship. Ethics 117/4: 623-648.

Stojanov K (2018) Educational Justice and Transnational Migration. Journal of Global Ethics 14/1: 34-46.

Andavolu, K (reporter) (2018) Separated by Birth - Vice, Series 6, episode 11. HBO. Sebescen A (producer). Aired: 23 June 2018.

UCLA Center for Labor Research and Education (2007) Undocumented Students. University of California-Los Angeles. Available at: https://www.labor.ucla.edu/publication/undocumentedstudents-unfulfilled-dreams/ (accessed 22 July 2018).

UNESCO Institute for Statistics (2019), Bangladesh: Education and Literacy. Available at: http://uis.unesco.org/country/BD (accessed 1 August 2019).

United Nations Department of Economic and Social Affairs (UN DESA), Population Division (2017) International Migration Report 2017: Highlights. Available at: https://www.un.org/ development/desa/publications/international-migration-report-2017.html (accessed 23 February 2020).

United Nations Department of Economic and Social Affairs (UN DESA), Population Division (2019). World Population Prospects 2019: Highlights. Available at: https://www.un.org/ development/desa/publications/world-population-prospects-2019-highlights.html (accessed 23 February 2020).

United Nations High Commissioner for Refugees (UNHCR) (2019), Bangladesh Refugee Emergency Population Factsheet. Available at: https://data2.unhcr.org/en/documents/ details/70840 (accessed: 31 July 2019).

U.S. Department of Education, National Center for Education Statistics, Schools and Staffing Survey (SASS) (2013) Private School Data File 1999-2000, 2003-04, 2007-08 and 2011-12. Available at: https://www2.ed.gov/about/offices/list/oii/nonpublic/statistics.html (accessed: 21 July 2018).

U.S. Department of Education (2018a) U.S. Network for Education Information. Available at: : https://www2.ed.gov/about/offices/list/ous/international/usnei/edlite-index.html and at: https://www2.ed.gov/about/offices/list/ous/international/usnei/international/edlite-interinfo.html (accessed 24 February 2020).

U.S. Department of Education (2018b) Laws and Guidance. Available at: https://www2.ed.gov/ policy/landing.jhtml?src=pn (accessed: 22 July 2018). 
U.S. Department of State (2018a) Schools Worldwide. Available at: https://2009-2017.state. gov/m/a/os/c1684.htm (accessed: 24 February 2020).

U.S. Department of State (2018b) Bangladesh, Dhaka: American School of Dhaka. Available at: : https://2009-2017.state.gov/m/a/os/219746.htm (accessed: 24 February 2020).

U.S. Department of State (2018c) Denmark, Copenhagen: Copenhagen International School. Available at: https://2009-2017.state.gov/m/a/os/219844.htm (accessed: 24 February 2020).

U.S. Department of State (2018d) France, Paris: American School of France. Available at: : https://2009-2017.state.gov/m/a/os/219846.htm (accessed: 24 February 2020).

U.S. Department of State (2018e) India, Mumbai: American School of Bombay. Available at: https://2009-2017.state.gov/m/a/os/219761.htm (accessed: 24 February 2020).

U.S. Department of State (2018f) Foreign Students in Public Schools. Available at: https:// travel.state.gov/content/travel/en/us-visas/study/student-visa/foreign-students-in-publicschools.html (accessed 10 January 2019). 